\title{
Providing Clinical Safety and Security for Nursing Students: Spontaneous Learning
}

\author{
Samaneh Parchebafieh ${ }^{1}$, Robabeh Memarian ${ }^{2^{*}}$, Zohre Vanaki ${ }^{3}$
}

\begin{abstract}
${ }^{1}$ Ph.D Student of nursing, Department of Nursing, Faculty of Medical Sciences, Tarbiat Modares University, Tehran, IRAN
${ }^{2}$ Ph.D Of Nursing, Assistant Professor Of Nursing, Supervisor, Department of Nursing, Faculty of Medical Sciences, Tarbiat Modares University, Tehran, IRAN ${ }^{3}$ Ph.D Of Nursing, Associate Professor Of Nursing, Advisor, Department of Nursing, Faculty of Medical Sciences, Tarbiat Modares University, Tehran, IRAN *Corresponding Author: memari_r@modares.ac.ir
\end{abstract}

Citation: Parchebafieh S, Memarian R, Vanaki Z. Providing Clinical Safety and Security for Nursing Students: Spontaneous Learning. Electron J Gen Med. 2020;17(3):em214. https://doi.org/10.29333/ejgm/7875

ARTICLE INFO
Received: 2 Sep. 2019
Accepted: 22 Jan. 2020

\begin{abstract}
Background: Clinical education environment safety and security plays an important role in the learning of nursing students. Various studies and authors' experiences show that there is a lack of learning in nursing students in the arena. The purpose of this study was to determine the effect of providing clinical safety and security on nursing students' learning.
\end{abstract}

Method: The research sample in this qualitative research consisted of 12 internship nursing students, 3 instructors and 4 nurses in one of the hospitals in Tehran, Iran. Educational intervention was conducted to empower the instructors in the areas of communication, educational strategies and physical environment reform by holding 3 workshops. After a semester, data was collected on nursing students' learning by semi-structured interview and field note. The content analysis method with a conventional approach was used to data analysis.

Results: The results revealed one main theme consisting of "spontaneous learning" and three sub themes including "learning nursing care", "the motivation for learning nursing care", and "effective interaction".

Conclusion: The main reason for spontaneous learning has been to improve psychological climate of the clinical environment (wards) by instructors. Acceptance of the student in the ward as a member of the care team and providing effective feedback were the most important factor in improving the psychological climate of the ward. This led to a motivation for care and spontaneous learning in students.

Keywords: clinical learning, safety and security, nursing student, spontaneous learning, qualitative research

\section{INTRODUCTION}

Learning clinical skills is one of the important factors in teaching nursing students (1). Clinical experience is essential for helping nursing students to apply theoretical concepts and skills in professional practice (2). Internship students work as part of a health professional team and take responsibility for providing safe care to a group of patients (3). The aim of this training course is to improve the quality of nursing care in the community and to provide community health. It is therefore important in nursing student clinical education (4).

In the theory of experiential learning, the environment plays an important role in learning, since the interaction of an individual with the environment leads to learning in the individual (5). The clinical environment encompasses all the conditions and stimuli that affect learning. The environment is composed of cognitive, social, cultural, affectional, emotional, motivational and educational factors. In this environment, many variables, including students, clinical educators and hospital wards staff, affect student learning (6). Nursing students need to practice in an environment that provides them personal and professional development (7). But along with the many benefits of clinical learning environments, this may be challenging, unpredictable, full of tension and constantly changing (8). Evidence suggests that students do not believe that all clinical environments lead to learning. Clinical learning often takes place in a design environment for clinical services rather than being conducted in an educational environment and lack of control over such an environment can affect student's quality of education (9). The results of a qualitative study revealed that nursing students in the bedside are affected by five main factors including the instructor, hospital staff, peers, patients and the physical environment (10). The results of Flott and Linden's study also showed that the clinical learning environment includes four characteristics that affect students' learning experiences: (1) physical space; (2) psychosocial and interactive factors; (3) organizational culture; and (4) teaching and learning components (11). One of the most important environmental factors affecting the learning process of students is psychosocial factors (8). The highest level of stress in internship nursing students is expressed in the unpleasant feelings (12). Several studies have focused on the broad dimensions of psychosocial factors. As a result of a study in Australia in 2018 by Anderson et al. it was shown that nursing students are not supported by nursing staff because nurses are not aware of their educational responsibilities towards students (13). The results of a study in 
Jamaica in 2015, by Lawal et al., showed that more than half of the students believed that the clinical environments were not a friendly environment and that it was necessary to correct these environments (14). The results of a study in Spain in 2018 by Suarez-Garcia et al also found that nursing students expressed above average stress in the clinical environment (15). The results of a study in 2016 by Jamshidi et al. showed that students in Iran face numerous challenges including ineffective communication, inadequate preparation, and emotional responses in clinical learning environments (16). Also, results of a study in Iran in 2014 by Dinmohammadi et al. showed the presence of non-supportive space in the bedside including contempt, blaming, refusing, exploiting, discrimination, bullying, lack of support and learning constraints that have dimensions of "vertical violence". In this article the origin of these behaviours were expressed nursing staff and clinical educators (17). Other studies have pointed to the inadequate support of nursing instructors from student learning (18) and instructors' violence including rigor, decrease student score, disrespect and hint of mistakes in the presence of others (19). These factors can be an obstacle to the learning and clinical qualifications of nursing students. But the results of the Levett-Jones and Lathlean study in 2009 showed that access to qualifications was achieved only after providing the prior needs of people regarding safety and security, attachment, healthy self-concept and learning (20). According to Abraham Maslow's theory, all humans need to be provided a sense of safety and security in the environment after their physiological needs have been provided (21). So the learning process's prerequisite is to provide security (1).

Extensive efforts have been made over the past decades to establish good learning. Use of learning theories and their application in education and learning were among these efforts. Understanding the learning theories that constitute the core of educational psychology is therefore important in teaching-learning process which helps instructors to extract effective learning principles from these theories, provide a suitable learning environment for learning, facilitate learning, increase productivity in educational system and coordination in education (22). The results of a review study in 2017 by Jayasekara et al. showed a total of 10 types of basic training models which included faculty-supervised practicum, preceptorship, education unit, joint appointment, secondment, affiliate position, internship, co-operative education, work-study, and undergraduate nurse employment. By examining each of these models, differences in the roles and responsibilities of students, faculty members and clinicians regarding the way of monitoring, teaching, learning and evaluation, as well as differences in the nature of communication between the academic and clinical organization can be seen (23). But none of these models mentioned how to supply positive teaching- learning atmosphere in the clinical environment. Teaching- learning atmosphere depends on the psychosocial climate of learning environments. From the perspective of nursing students, the most important feature of a good learning environment is to have an ontological security (24). In such a safe work environment, students can influence the nursing professional development. The sense of security includes physical and psychological security (25).

The researchers' experiences in this study, as well as surveys conducted through observation and interviews with instructors, clinical nurses and nursing students, showed that instructors do not use a specific scientific method to provide internship nursing students' safety and security in the clinical environment. On the other hand, several studies have focused on the importance of the safety and security of the clinical environment in student learning. In this research, the researcher is trying to improve the clinical environment and explore the effects of improving the safety and security of the clinical environment on the clinical learning of internship students. The aim of this qualitative study is to answer the question of how the safety and security of the clinical environment affect internship students' learning.

\section{MATERIALS AND METHODS}

\section{Design}

The methodology of this research is qualitative and was carried out in 2016. Qualitative research allows the researcher to gain insights into the participants' inner experience and to find out how the meanings are formed through culture and within it, and it discovers it instead of examining variables (26). The researchers in this study sought to conduct educational interventions to provide safety and security of the clinical environment by educating instructors to examine their effects on the learning of clinical education by students.

\section{Data Collection}

The research environment consists of one of the hospitals in Tehran, Iran, which has been collaborating with the Nursing and Midwifery Faculty for clinical education since 13 years ago. In addition to the first author of this article, 3 instructors are involved in clinical education of nursing students. In Iran, instructors do not receive any special training before starting clinical education of nursing students. The problem of learning deficiency and lack of safety and security of the environment in the presence of poor learning atmosphere was confirmed by interviewing students, instructors and nursing staff. The instructors' experience of clinical learning was 10, 8 and 4 year.

In order to improve safety and security in the bedside, there was a need for intervention to empower the instructors. By reviewing the interviews and studying the literature on this subject such as "Self Promotion Model" in nursing care management (25), it became clear that there was a need for reforming communication, educational strategies, and the physical environment. Therefore, 3 workshops were held on the above issues with the aim of empowering instructors. After conducting these 3 four-hour workshops, trainers were asked to use the trained courses in the bedside. An example of the issues in these 3 workshops is shown in Table 1.

One semester after the implementation of the training provided to the instructors, learning of nursing students was investigated by interview method and field notes, from the four groups of internship nursing students (35 students) in the last semester in groups of 8 or 9 who were referred to the hospital for medical and surgical nursing courses. After obtaining informed consent from the students participating in the study, internship courses were held 3 days a week for 6 weeks ( 2 units, equivalent to 18 days) at this hospital.

At the end of each internship period, data collection was done by qualitative interviews and field notes with 12 nursing students, 3 instructors and 4 nurses in the rest room of the staff in the hospital wards by the first author to determine whether 
Table 1. Ways to ensure the safety and security of the clinical learning environment

\begin{tabular}{ll}
\hline Domain & Providing safety and security in clinical environment \\
\hline Communication & $\begin{array}{l}\text { How to establish appropriate professional communication with students and nursing staff - nursing staff support - How } \\
\text { to create a friendly atmosphere in the bedside, such as avoiding unpleasant words - Encouraging students- having } \\
\text { reasonable expectations of the student - Respecting students and having the same behavior for all of them - Student co- } \\
\text { operation with the ward when needed }\end{array}$ \\
\hline $\begin{array}{l}\text { clinical education } \\
\text { strategies }\end{array}$ & $\begin{array}{l}\text { Modify the clinical lesson plan - Identify daily training goals by coaches - Assign } 1 \text { to } 3 \text { patients to each student based on } \\
\text { the ability- Instructor role model to provide patient care - Correct student evaluation and give appropriate feedback - } \\
\text { Gain nurses' cooperation in clinical education of students }\end{array}$ \\
\hline physical environment & Introducing the dressing room and rest room to students on the first day of internship
\end{tabular}

Table 2. Sample interview with students

\begin{tabular}{ll}
\hline Interview & Initial codes \\
\hline$(23$ Y/O, No. 2) & - Here we were treated like personnel \\
They behaved with us like personnel. In the 18 days that we came & - Respect us \\
here, we were treated like personnel. We felt as if we were & - Create a sense of usefulness \\
respected, as if we were useful. & - Sense of being \\
\hline
\end{tabular}

Table 3. Two examples of the analytic process, at first semantic units were condensed; then coded and there after codes were sorted into subthemes

\begin{tabular}{|c|c|c|c|c|}
\hline Interview text & Semantic unit & Code & Open coding & Subtheme \\
\hline $\begin{array}{l}\text { We were studying. But } \\
\text { our studying was not due } \\
\text { to the fact that our score } \\
\text { did not decrease; it was } \\
\text { because of the fact that } \\
\text { the patient learned } \\
\text { something from us as a } \\
\text { nurse who was } \\
\text { competent. (Student } \\
\text { number } 11,23 \text { years old). }\end{array}$ & $\begin{array}{l}\text {-our studying was not } \\
\text { due to the fact that our } \\
\text { score did not decrease } \\
\text {-We were studying } \\
\text { because of the fact that } \\
\text { the patient learned } \\
\text { something from us as a } \\
\text { nurse who was } \\
\text { competent. }\end{array}$ & $\begin{array}{l}\text { - Student further study } \\
\text { due to her need for } \\
\text { improved care }\end{array}$ & $\begin{array}{l}\text {-The motivation to do } \\
\text { scientific care }\end{array}$ & $\begin{array}{l}\text {-The learning motivation } \\
\text { for nursing care from the } \\
\text { patient }\end{array}$ \\
\hline
\end{tabular}

students learn the care of the patient at the bedside. All interviews took place between October and December 2016 and lasted between 20 and 40 minutes. Interviews were recorded by the voice recorder and were transcribed immediately. Purposeful sampling continued until data saturation. The most common technique for collecting information in qualitative research is interviewing. Interviews are appropriate for researchers seeking to understand the participants in the world and their experiences (27). Quotes from the notes in the field are useful to show or legitimize the concepts (28). All field notes were revised and were encoded like the text of the interviews. Sample questions asked from the participants were:

Students: Describe one day of your internship in this hospital?

Instructors: How do you train your students to take care of the patient?

Staff Nurses: What role do you play in teaching nursing students?

The dimensions of the problem were further examined by follow-up questions.

\section{Data Analysis}

For data analysis, content analysis with a conventional approach was used. Conventional content analysis is usually appropriate, as the researchers intend to immerse themselves in the data to allow new insights to emerge (29). A sample of the interview with the student along with the initial codes is shown in Table 2.

Accordingly, researchers repeatedly reviewed the text of interviews and field notes on the basis of the research question, broken down into the smallest units of semantics. A list of semantic units was prepared and reviewed many times to find the semantic units in a sub-class based on the axis of reference. Subsequently, with the same decreasing trend, subclasses associated with each other were placed in one class.

Table 3 shows an example of how the themes are formed. The main theme is an abstract concept that is represented by the concept of the entire interview.

All researches should be rigorously examined (30). Rigor of study was provided with the following steps: In order to guarantee credibility, in addition to permanent and long-term presence with research samples, the findings of this study were presented to the participants. Their opinions about the coordination of findings with their experiences were expressed. Researchers ensured the verifiability of this research by maintaining the documentation at all stages of the research, clarifying how the results from the data were obtained, the long-term contact with the data, as well as attempting to obtain opinions from others in this regard. The research dependability was confirmed by data auditing and recording details of the coding and classification steps of the data as well as using comments by colleagues.

It should be noted that the code of ethics received was IR.TMU.REC.1395.332 from the research deputy of Tarbiat Modares University. The consent forms that were introduced by the vice chancellor of the Tarbiat Modarres University were completed by these students. 


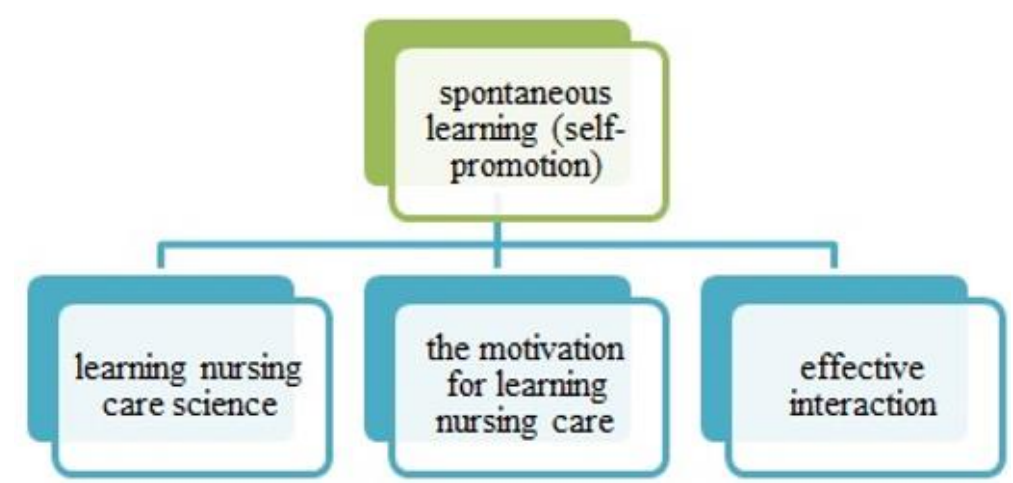

Figure 1. Providing safety and security in the clinical environment of nursing students created a main theme including spontaneous learning with 3 sub themes

\section{RESULTS}

Data analysis revealed a major theme consisting of "spontaneous learning (self-promotion)" and 3 sub themes including "learning nursing care science", "the motivation for learning nursing care", and "effective interaction" (Figure 1). Below are examples of interviews in each area.

\section{The Main Theme: Spontaneous Learning (Self-promotion)}

By providing safety and security in the clinical learning environment, which was a primary responsibility of nursing instructors, students were looking for further learning and learning without being forced or fear of instructors, and they improved their learning and improved their care of the patient. Instructors improved the conditions of learning environments and resulted in learning responsibilities and spontaneous efforts for learning. Below are 3 sub themes of spontaneous learning (self-promotion).

\section{Learning nursing care science}

Four categories of scientific nursing care including "deep and spontaneous learning following a more effective participation in the ward", "regular learning and care", "collaborative learning supported by classmates and staff nurses" and "learning of scientific care, a factor in reducing student mistakes". Correcting the strategies of educators' clinical education, students were able to undertake scientific care and learn deeply by using the nursing process model to provide case method care. One of the nurses said: "Previously, students experienced superficial learning, but now learning is much more comprehensive and deeper" (male staff nurses). Also, most students felt the need for further study. As a student said "The good thing about this internship course was that, in order to be able to provide nursing care based on the patient nursing process model, we had to study illness. We recognized the illness, the complications of the medications, it helped a lot...we have raised our knowledge, rather than just doing the clinical work "... (Student No. 5).

Also, the clarity of the goals and tasks of learning from the first day of the internship and having the pattern contributed to the regularization of learning and therefore nursing care, as the student stated: "We did not know what we should ask the patient before. We did not know what to look for. The patient assessment form that the instructor gave us helped us. Now we know what to do. What we want to know. Previously, we asked 2 sporadic questions. The patient assessment was ordered by our form" (Student No. 10).
The participation of nursing staff increased for student training, as one of the instructors said: "Nurses would like to attend student conferences within the ward (instructor C).

The instructor reduced students' mistakes by creating an optimal and safe atmosphere in the ward. It seems to be part of the students' mistakes because of the fear of abusive behaviours from instructors. One student said: "Our instructor was very good here. Well, in my opinion, the goodness of the instructor means that under any circumstances, if there is any misconduct by the student, the behaviour of the instructor is not humiliating and insulting. ... When someone tells me about my performance and points out my mistakes, I'm not afraid of that instructor or scoring, my confidence will rise and I won't have any stress I will not make mistakes the next time" (Student No. 4).

\section{The motivation for learning nursing care}

One of the most effective changes in promoting learning was to create a student's enthusiasm of learning nursing care. Its categories include "the enthusiasm of scientific care," "the continued presence of the student and the instructor in the ward," "the student's effort to learn through effective communication with the instructor," "increasing student responsibility", "creating a sense of self-efficacy in the student", "learning without fear," "improving communication," and "increasing student access to facilities in hospital wards ". Due to the large number of categories, only a few examples are given.

A large number of students with different vocabulary expressed an interest in caring for their internship: "Students who do not work always told me that they were skipping previous internship courses. But in this internship course, they were assigned the patient in the case method, and they had to take care of the patient themselves, I saw that they are enthusiastic for caring. So I thought it was a lot better"(student No. 7).

One of the nurses said: "Student performance has improved, both in terms of improving procedures and in terms of patient assessment and patient and family education. So that they spend more time with the patient" (Female staff nurse). Moreover, the change in the work process of instructors was quite tangible for nurses. They also said there has been an increased presence of the instructors in the ward: "instructors have changed ... This is very important, it was not so before. Now trainers are more in attendance, they are more accountable." (Female staff nurse). 
By learning the communication skills by instructors, they established good communication with the students. Communication aimed at providing safety and security. The result was to create a sense of confidence in the student towards the instructor and lack of fear of being chastised by them. "Despite the relationship between us as a studentinstructor, our relationship was very friendly so this could make it much easier for us to communicate. If they wanted something from us, we would be interested in it, not from fear and compulsion," said the student No. 11. As the text of the interview shows, the interest in caring and learning increased with the improvement of the communication between the instructors and the students.

Students also experienced a sense of usefulness, increased self-esteem, and a sense of becoming a nurse, and this meant a sense of empowerment and self-efficacy in the student: "We can now ask a question from a patient ... our self-confidence to speak increased. Previously, we did not ask the patient a lot of questions"(student No. 6).

Students provided care, without fear of negative reactions of staff nurses. One student said: "I was afraid to say to a nurse I can give the patient medicine. Maybe something would happen to the patient. Then the nurses would say I am at fault, but now I'm not afraid" (student No. 2). While students said before the intervention, they tried to hide in the hospital so that they would not be required to take care of the patient so that they would not be subjected to being insulted by the nurses.

Student communication has improved with instructors, nursing staff as well as patients. As the student stated, "The instructor is very good ... We are all satisfied. We no longer feel out of place. We are used to talking to the patient when we have medicine; we are used to always being with the patient, or with the staff. Staff Nurses are really Okay ... "(student No. 2).

One of the benefits of intervention to improve safety and security was students were provided more access to the patient files and ward facilities: "This was the first ward that provided us the patient file and kardex. Previously, no one provided us with this facility. It was the first internship course that we really did nursing care "(student No. 7).

\section{Effective interactions}

Learning how to establish effective interactions between instructors, nursing students and staff nurses was one of the main effects of intervention to improve the safety and security of the clinical environment. "Establishing trust between patient, students and nursing staff," "Interpersonal respect in the ward", "Student acceptance in the ward" and "Student, personnel and patients' satisfaction," is among the categories of effective interactions.

Student stated: "I learned from this internship course that I could have an effective relationship with the patient and the patient's relatives" (student No. 5). From the viewpoint of nurses, the students' communication with them improved, and this enabled better learning: "Our interaction with students has become much greater. Now, students are more closely connected with us...We also communicate with them more calmly "(Female staff nurse).

The student stated: "When the instructor comes in the ward, there is respect in the ward, both between the nurses and the instructor ... Nurses were asking us to work with respect ... Nurses have a very good relationship with us, it was respect" (Student No. 12). When the instructor's behavior was respectful to students and nursing staff, students and staff reciprocated this respectful behaviour with the student and instructor, and so the mental atmosphere improved.

One of the most influential factors in student learning was the acceptance of students in the ward as a member of the care team. One of the students said: "Here, we were treated like the staff. During the 18 days that we were in this ward, they treated us as personnel." A much respected person, as if you were a useful person. "(Student No. 2). With respect to the student and his acceptance in the ward, the sense of belonging in the student was formed and therefore the student was more interested in learning and improving their care.

The benefits of implementing this intervention to ensure the safety and security of the clinical environment created satisfaction in the student, staff and patient. Creating a sense of satisfaction in people is a motivating factor for improving performance. One of the nurses said: "Now the patients are very satisfied with the students. The satisfaction of the patients is very high. The patient's satisfaction is very important, because in the hospital, what is very important is the right of a patient, because if they are dissatisfied, we are dissatisfied. But now that they are satisfied with the student, it is much better. The head nurse is also satisfied ... we are also satisfied. "(Female staff nurse).

One of the head nurses of ward expressed answering students' questions and securing them in the ward, as a student satisfaction factor and said: "We saw the satisfaction of the students ... always going on with a good memory when students go from our ward, because they found that we gave them a sense of security and self-confidence. Because we answered all their questions" (Male Head nurse).

\section{DISCUSSION}

The results of this study showed that internship nursing students achieved spontaneous learning (self-promotion) by providing safety and security. For as much as self-promotion in learning is one of the educational goals in different medical terms, the implementation of this study was able to help students achieve this important goal by providing safety and security to the environment.

Despite the importance of the physical environment in nursing students' clinical learning, it seems that the main reason for the change in student learning has been the promotion of communication and positive psychological development in the bedside. During the workshops, instructors learned how to improve psychological climate of the clinical environment.

Instructors understood that students needed to be accepted and respected in a clinical learning environment. The results of the study entitled "Facilitating factors in clinical education in nursing" by Elçigil and Sarı in 2011 showed that the effects of the clinical environment on learning focused on human relationships, not physical conditions. In this study, students reported that when nurses showed effective communication skills, students learned more and felt themselves as a part of a care team.Positive feedback from nurses also increased their motivation for clinical learning and enabled students to identify their weaknesses and helped them improve their knowledge and skills. Having a sense of importance in the care team has increased the motivation to 
learn (31). Therefore, it seems that student learning more than any other factor affects the relationships between individuals. As a result of improving communications between instructors, students and nursing staff, students were accepted as a part of a care team. The sense of belonging to the environment was created in the students, and thus they became accountable. The responsibility of the student at the bedside was to accept the responsibility of taking care of the patient, as well as assuming responsibility for learning by himself and eventually, spontaneous learning.

In addition to the correction of communication, the correction of clinical education strategies was effective in making students interested in taking care of the patient. Effective feedback to students was one example of the correction of clinical education strategies. Rahimi et al., in a review article in 2016, argued that providing feedback is an essential and integral part of learning. The feedback leads to learning and progress, and causes the student to stay on track (32). The results of Orden et al. in 2018, entitled "The learning experiences of nursing students in surgical clinics reflected in reflection reports" also showed that the presence of students in the clinical care team and positive feedback has increased their motivation (33). How to provide effective feedback to the students was part of the training strategies that were taught to instructors.

The problem of care planning for the patient by instructors and students is an obstacle to learning the clinical skills required for students (34). Students learned how to manage nursing care from the patient by correcting the strategies of clinical instructors and providing environmental conditions for patient care. By improving student performance in patient care, the trust of the patient, the instructor and the nursing staff increased for the student and this increased the student's passion for caring. The results of a qualitative study by Elisabeth et al showed that educators attempted to create trust as the basis for communication between themselves and students in order to create a sense of security in students. In this study, trust-based communication is considered vital for students' learning (35).

By intervening, students were encouraged to take care of the patient. However, before the intervention, most of the student's educational time was spent in the classroom but after the intervention, the instructors learned that the best way to learn the care is to take care of the patient's bedside. The results of the study showed that students feel satisfied and successful with caring for patients. Also, they became more interested in their careers since the students understood the care process and the results of their care in the patient (33). So, encouraging students to offer scientific nursing care would create an enthusiasm for care and thus more students learning (36).

In sum, all of these factors led the students to feel the safety and psychological security and thus to take care of the patient with enthusiasm. This required the empowerment of instructors on the clinical education of nursing students. Because, as stated, before the intervention was implemented, the instructors did not receive any training on the educational strategies at the bedside. But after educating them, they acted as agents of change in the bedside. They were able to play an important role in improving clinical safety and security with correction of psychological climate and educational strategies and finally, they gave fresh impetus to the learning of the students at the bedside. Eventually the student became a spontaneous learner.

\section{CONCLUSION}

The results of this study showed that spontaneous learning in nursing students was enhanced by providing safety and security to the clinical environment by instructors. Modifying the clinical education of instructors played an important role in improving student learning. Therefore, ensuring the safety and security of the clinical environment by educating the instructors at the onset of clinical education is considered essential for nursing faculties. Instructors' training on reforming educational strategies, modifying the physical environment and improving communication led to correction of psychological climate in wards by instructors and increased motivation of care and learning in students and led them to spontaneous learning.

Qualitative research methodology has been able to reveal how to teach nursing students after providing safety and security of clinical environment and shows that the safety of learning environment, especially correction of the psychological climate of the wards, can lead to spontaneous learning in nursing students.

The strength of this study was the very good cooperation of nursing staff and instructors in providing safety and security to the clinical environment. One of the limitations of this study was the willingness of researchers to engage more of the instructors in this intervention, but it was not plausible due to the limited capacity of the hospital to inter the student and instructor. Other limitations of this study were purposeful sampling and female students participated in the study.

It is suggested that in nursing faculties, the importance of improving the psychological climate of clinical environments is further emphasized. Regarding the important role of instructors in creating the safety and security of the clinical environment, training courses for instructors about correction of communication, effective interaction, and the modification of educational strategies and how to provide physical facilities for nursing students before entering clinical education field as well as periodically continuing education will be held; Because the implementation of clinical education standards has a tremendous effect on the learning of nursing students.

\section{ACKNOWLEDGEMENT}

This article is a part of a PhD dissertation in nursing which was approved by the Medical Ethics Committee of Tarbiat Modares University. The authors would like to thank all student nurse interns, instructors, nurses, and educational supervisor of this Hospital. This research received no specific grant from any funding agency in the public, commercial, or not-for-profit sectors.

\section{Conflict of Interest}

The authors declare no conflict of interest. 


\section{REFERENCES}

1. Wighus M, Bjørk IT. An educational intervention to enhance clinical skills learning: Experiences of nursing students and teachers. Nurse Education in Practice 2018;29:143-9. https://doi.org/10.1016/j.nepr.2018.01.004 PMid:29353107

2. Perry RD, Press MM, Rohatinsky N, et al. Pilot study: Nursing students' perceptions of the environment in two different clinical models. International Journal of Nursing Sciences 2016;3:285-90. https://doi.org/10.1016/j.ijnss.2016.07.001

3. Nevin M, Neill F, Mulkerrins J. Preparing the nursing student for internship in a pre-registration nursing program: Developing a problem based approach with the use of high fidelity simulation equipment. Nurse education in practice 2014;14:154-9. https://doi.org/10.1016/j.nepr.2013.07.008 PMid:23958078

4. Mahmoudifar Y. Field clinical educations in the view of educational instructors and nursing students Journal of Educational Strategies 2009;2:7-12 [Persian]

5. Kolb DA, Boyatzis RE, Mainemelis C. Experiential learning theory: Previous research and new directions. Perspectives on thinking, learning, and cognitive styles 2001;1:227-47. https://doi.org/10.4324/9781410605986-9

6. Moattari M, Ramazani S. Nursing students' perspective toward clinical learning environment. Iranian Journal of Medical Education 2009;9:137-45 [Persian]

7. Arkan B, Ordin Y, Yılmaz D. Undergraduate nursing students' experience related to their clinical learning environment and factors affecting to their clinical learning process. Nurse education in practice 2018;29:127-32. https://doi.org/10.1016/j.nepr.2017.12.005 PMid:29274524

8. Baraz S, Memarian R, Vanaki Z. Learning challenges of nursing students in clinical environments: A qualitative study in Iran. Journal of education and health promotion 2015;4. $\quad$ https://doi.org/10.4103/2277-9531.162345 PMid:26430679 PMCid:PMC4579762

9. Shivers E, Hasson F, Slater P. Pre-registration nursing student's quality of practice learning: Clinical learning environment inventory (actual) questionnaire. Nurse education today 2017;55:58-64. https://doi.org/10.1016/j.nedt.2017.05.004 PMid:28528125

10. Serçekuş P, Başkale H. Nursing students' perceptions about clinical learning environment in Turkey. Nurse education in practice 2016;17:134-8 https://doi.org/10.1016/j.nepr.2015.12.008 PMid:26787194

11. Flott EA, Linden L. The clinical learning environment in nursing education: a concept analysis. Journal of advanced nursing 2016;72:501-13. https://doi.org/10.1111/jan.12861 PMid:26648579

12. Tahery N, Kaiali M, Yaghoobi M, et al. The stressors of clinical training in nursing students-Abadan nursing faculty (2009). Modern Care Journal 2011;8:159-65.

13. Anderson C, Moxham L, Broadbent M. Teaching and supporting nursing students on clinical placements: Doing the right thing. Collegian 2018;25:231-5. https://doi.org/10.1016/j.colegn.2017.06.005

14. Lawal J, Weaver S, Bryan V, et al. Factors that influence the clinical learning experience of nursing students at a Caribbean school of nursing. Journal of Nursing Education and Practice https://doi.org/10.5430/jnep.v6n4p32
15. Suarez-Garcia J-M, Maestro-Gonzalez A, Zuazua-Rico D, et al. Stressors for Spanish nursing students in clinical practice. Nurse education today 2018;64:16-20. https://doi.org/10.1016/j.nedt.2018.02.001 PMid:29454874

16. Jamshidi N, Molazem Z, Sharif F, et al. The challenges of nursing students in the clinical learning environment: a qualitative study. The Scientific World Journal 2016. https://doi.org/10.1155/2016/1846178 PMid:27366787 PMCid:PMC4913003

17. Dinmohammadi M, Peyrovi H, Mehrdad N. Undergraduate student nurses' experiences in clinical environment: Vertical violence. Iran Journal of Nursing 2014;27:83-93. https://doi.org/10.29252/ijn.27.90.91.83

18. Mirzaei R, Borhani F, Fasihi Harandi T. Student's perception of clinical learning environment. 2014.

19. Rahnama M, Yaghoubinia F, Firouzkouhi MR, et al. Nursing students' experiences of clinical education setting. Medical-Surgical Nursing Journal 2015;4:56.

20. Levett - Jones T, Lathlean J. The ascent to competence conceptual framework: an outcome of a study of belongingness. Journal of Clinical Nursing 2009;18:2870-9. https://doi.org/10.1111/j.1365-2702.2008.02593.x PMid:19220619

21. Brunner LS. Brunner \& Suddarth's textbook of medicalsurgical nursing: Lippincott Williams \& Wilkins. 2010.

22. Baraz S. Explaining the experiences of nursing students' learning process and provide prescriptive model: Tarbiat Modares University. 2014.

23. Jayasekara R, Smith C, Hall C, et al. The effectiveness of clinical education models for undergraduate nursing programs: A systematic review. Nurse education in practice. 2017. https://doi.org/10.1016/j.nepr.2017.12.006 PMid:29272736

24. Warne T, McAndrew S. Painting the landscape of emotionality: colouring in the emotional gaps between the theory and practice of mental health nursing. International Journal of Mental Health Nursing 2008;17:108-115. https://doi.org/10.1111/j.1447-0349.2008.00518.x PMid:18307599

25. Baraz S (2014) Explaining the experiences of nursing students' learning process and provide prescriptive model. Tehran: Tarbiyat Modares University.

26. Dehghan Nayyeri N, Fakhr Movaheddi A, Esmaeili T, et al. (2012) Basics of Qualitative Research: Techniques and Prosedures for Developing Grounded Theory. Corbin, Juliet Strauss, Anselm. Corbin J, Strauss A, translator. Tehran: Andishe Rafie.

27. Holloway I (2005) Qualitative research in health care. Printed in the Poland by OzGraf. S.A.: McGraw-Hill Education (UK).

28. Corbin J, Strauss A. Basics of Qualitative Research; Fourth e, editor. United State of America: SAGE Publication. 2015.

29. Hsieh H-F, Shannon SE. Three approaches to qualitative content analysis. Qualitative health research 2005;15:127788. https://doi.org/10.1177/1049732305276687 PMid:16204405

30. Ryan F, Coughlan M, Cronin P. Step-by-step guide to critiquing research. Part 2: qualitative research. British journal of nursing 2007;16:738-45. https://doi.org/10.12968/bjon.2007.16.12.23726 PMid:17851363

31. Elçigil A, Sarı HY. Facilitating factors in clinical education in nursing. Nursing Clinical Education 2011;4:67-71. 
32. Rahimi M, Ehsanpour S, Haghani F. The role of feedback in clinical education: Principles, strategies, and models. Journal of Medical Education and Development 2016;10:264-77 [Persian[

33. Ordin YS, Bilik Ö, Damar HT, et al. The Learning Experiences of Nursing Students in Surgical Clinics Reflected in Reflection Reports. Journal of Qualitative Research in Education - JOQRE 2018;6:106-20. https://doi.org/10.14689/issn.2148-2624.1.6c3s5m

34. Aboshaiqah AE, Roco IM, Pandaan IN, et al. Challenges in the Clinical Environment: The Saudi Student Nurses' Experience. Education Research International 2018. https://doi.org/10.1155/2018/3652643
35. Elisabeth C, Christine W-H, Ewa P. Teaching during clinical practice: Strategies and techniques used by preceptors in nursing education. Nurse education today 2009;29:522-6. https://doi.org/10.1016/j.nedt.2008.11.012 PMid:19108935

36. Shahsavar F, Kheirollahi A, Jafarzadeh M, Hedayati M. SUMO4 M55V Polymorphism is associated with diabetic nephropathy in Iranian type 2 diabetes patients. Life Science Journal 2013;10(5S):485-8. 